\title{
THE SENSING PROPERTIES OF CARBON NANOTUBE FILLED COPOLYMERS FOR VOC VAPORS DETECTION
}

\author{
Rostislav SLOBODIAN, Robert OLEJNÍK, Jiři MATYÁŠ, Petr SLOBODIAN \\ Tomas Bata University in Zlín, University Institute, Centre of Polymer Systems, Zlín, Czech Republic, EU, \\ rslobodian@utb.cz, oleinik@utb.cz,.matyas@utb.cz, slobodian@utb.cz
}

https://doi.org/10.37904/nanocon.2020.3695

\begin{abstract}
Nowadays, carbon nanotubes are a widely available material, especially multiwall carbon nanotubes. In addition to many other applications, they find use in all kinds of sensors, like deformation, motion, tensile and pressure responsive elements. Numerous applications in sensors for volatile organic compounds (VOCs) are reported as well, nevertheless, they mainly suffer from low selectivity. Therefore, in this research, a sensor containing MWCNTs dispersed in a functional polymer matrix was prepared. As a polymer matrix, styreneisoprene-styrene elastomer was chosen. The standard sensing mechanism of entangled MWCNTs is based on the quality of the contacts (charge transfer) between the individual nanotubes. In the prepared nanocomposite, the mechanism is modified due to the presence of the otherwise non-conductive matrix. The changes of conductivity depend on the response of the percolating nanotube filler network to the swelling of the polymer matrix due to adsorption of VOCs. The tested gas substances have high values of diffusion coefficient for the polymer, so they have a quick response. Then, the selectivity is ensured by differences in solubility of the tested VOCs in the polymer. The effect was demonstrated for four VOCs differing by their affinity to the polymer matrix, namely, heptane, toluene, acetone, and ethanol.
\end{abstract}

Keywords: Carbon nanotubes, copolymer nanocomposite, organic vapour sensing, gas sensor

\section{INTRODUCTION}

Carbon nanotubes (CNTs) are one of the allotropic forms of carbon that attract considerable attention nowadays. The arrangement of sp2 carbon atoms looks like a graphene "honeycombs" sheet that is twisted into a tube. The origin of CNTs can be traced to their discovery in Japan by Sumio lijima in 1991 [1]. These nanotubes have unique electrical and mechanical properties and have become very popular for scientific activities around the world. The nanotubes can be produced either in the single-wall form or in the form of multiwall carbon nanotubes (MWCNTs). The production of MWCNTs is relatively simple, and they are available in a large variety of commercial brands. Moreover, they have a large specific surface area and good electrical conductivity [2].

The electrical conductivity of clusters and structures from CNT is very sensitive to the absorption of volatile organic compounds (VOCs), and these structures have excellent properties as sensors for the detection of vapours and gases [3]. Adsorption/desorption of gaseous molecules occurs due to the interaction of organic vapours with the surface of carbon nanotubes. This process causes a change in electrical resistance. On the other hand, the electrical conductivity response of structures made from bare CNTs to the gaseous molecules suffers from low selectivity. Interaction with any electron-donating molecule causes an increase of the conductivity while interaction with any electron acceptor molecules results in a decrease of the conductivity [4]. Therefore, we propose to prepare the entangled CNT structure in a polymer matrix, which will selectively interact with various VOC molecules. It is expected that a permeable thin soluble elastomeric material like styrene-isoprene-styrene (SIS) co-polymer is the most promising candidate for this purpose. 


\section{MATERIALS AND METHODS}

For composite preparation, multiwall carbon nanotubes (MWCNTs) were used. The purified MWCNTs produced by chemical vapour deposition (CVD) from an acetylene precursor were delivered by Sun Nanotech Co. Ltd., China. The nanotube diameter was $10-30 \mathrm{~nm}$, length $1-10 \mu \mathrm{m}$, purity $>90 \%$ and specific electrical conductivity $0.12{\mathrm{~S} . \mathrm{cm}^{-1}}^{-1}[5,6]$

The polymer matrix was copolymer Kraton D SIS (styrene-isoprene-styrene), which is a thermoplastic elastomer with a combination of advantageous properties such as high strength, low hardness and low viscosity in solution processing. MWCNTs dispersion was prepared in solution of Kraton in toluene, and it was sonicated at $40{ }^{\circ} \mathrm{C}$ for 15 minutes using the ultrasonic device UP $400 \mathrm{~S}$. The concentration of MWCNTs in the dispersion was $11 \mathrm{wt}$ \%. Interdigitated copper electrodes were made from Cuprexite (a layered structure made of $1 \mathrm{~mm}$ epoxy/glass laminate coated with a $35 \mu \mathrm{m}$ thick $\mathrm{Cu}$ film by etching with a $30 \%$ solution of $\mathrm{FeCl}_{3}$ in water at room temperature. The copper electrodes were soaked in the copolymer MWCNTs dispersion for 10 seconds to form an active scanning layer on the surface, and they were then allowed to dry at $25{ }^{\circ} \mathrm{C}$ for 48 hours. The thickness of the ensuing nanocomposite layer was about $150 \mu \mathrm{m}$. [7]

To analyze the surface of the polymer composite, Phenom G2-Edlin scanning electron microscope (SEM) was used.

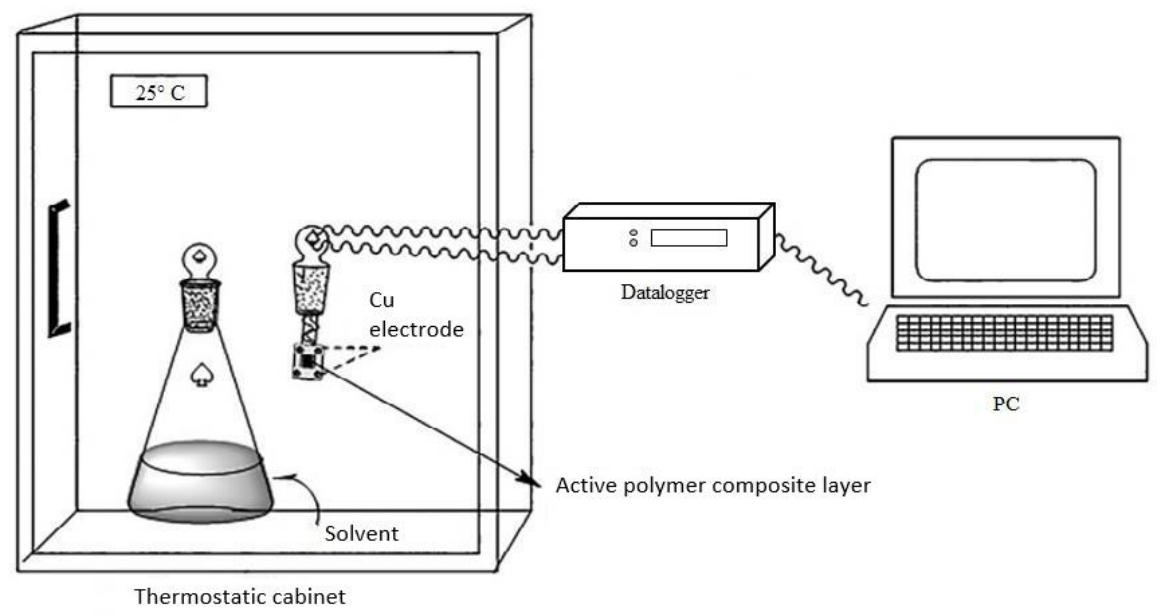

Figure 1 Experimental system for measuring resistance change

The electrical resistance was measured using a Multiplexed Data Logger 34980 connected to a PC (Figure 1), where the measured resistivity data was read every $1 \mathrm{~s}$. The electrode with the active scanning layer was closed in an Erlenmeyer flask containing an organic solvent. These organic vapours were either an aliphatic hydrocarbon (heptane), aromatic hydrocarbon (toluene), ketone (acetone) or alcohol (ethanol). It took 6 min before the electrode with an active layer detected organic solvent vapours by changing its electrical resistance. The nanocomposite electrical resistance was quantified by the relative electrical resistance change defined as

$\Delta \mathrm{R} / \mathrm{R}_{0}=\frac{\left(\mathrm{R}-\mathrm{R}_{0}\right)}{R_{0}}$

where:

$R_{0}$ - is the electrical resistance of the composite before the exposition to vapour $(\Omega)$

$R$ - is the resistance during the exposition of the holder with the coated interdigitated electrode by the nanocomposite $(\Omega)$ 
After this time, the electrode was pulled out of the flask and the desorption cycle was started in the thermostatic cabinet for $6 \mathrm{~min}$ at $25^{\circ} \mathrm{C}$. These cycles of absorption/desorption were repeated five times. The measurement was made under atmospheric pressure, at a temperature of $25{ }^{\circ} \mathrm{C}$ and relative humidity of $40 \%$ in the thermostatic cabinet [7].

\section{RESULTS AND DISCUSSION}

Photographs of the interdigitated electrode substrate and the prepared sensor can be seen in Figure 2a) and $\mathbf{b}$ ), respectively. The soaking method was used to achieve a good surface coverage. The surface morphology of the cast polymer composite layer is shown in images in Figures $\mathbf{2 c}$ ) and $\mathbf{d}$ ). The relief structure the composite resembles an irregular landscape of a coral reef. Fissures and valleys of white appearance can be observed within the continuous black polymer composite phase. Small bright homogeneously distributed spots are observable in the polymer matrix. These spots may be attributed to asperities caused by local entanglements of CNTs. Thus, the composite layer should be capable of detection of macroscopic electrical resistance change due to interconnected CNT structures.

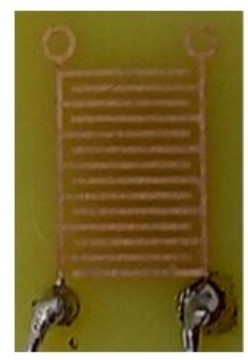

(a)

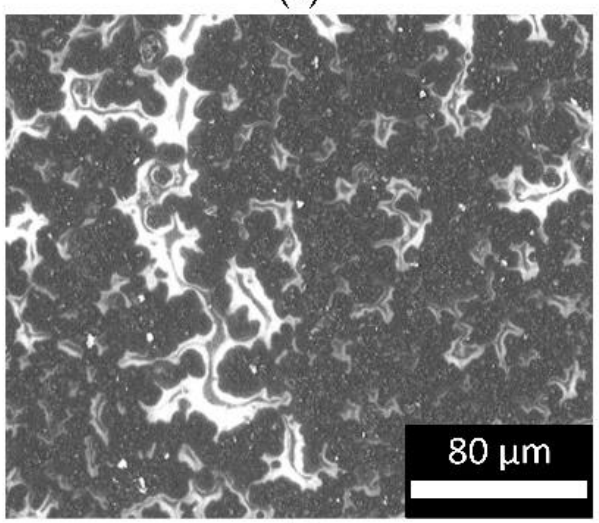

(c)

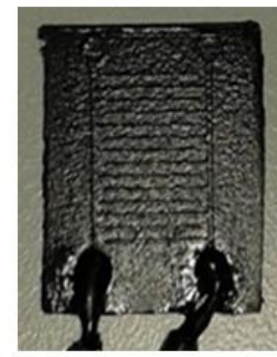

(b)

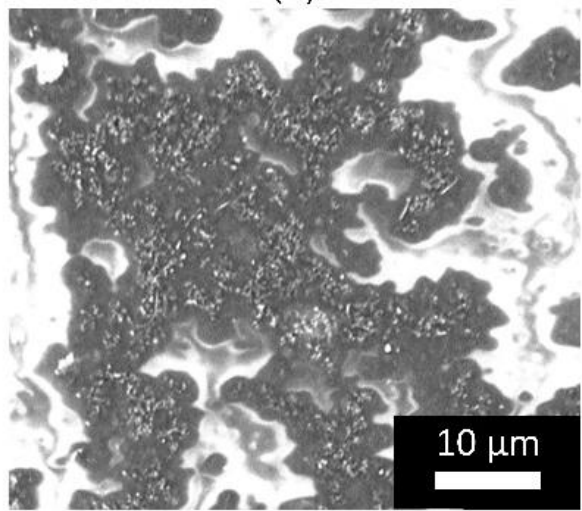

(d)

Figure 2 Photographs of (a) the copper interdigitated electrode substrate and (b) the electrode with a layer of polymer composite. SEM micrographs at lower (c) and higher (d) magnification

As stated earlier, the MWCNT/SIS composite sensor was exposed to the vapours of four organic solvents, namely toluene, acetone, ethanol, and heptane. The responses of the sensors to each of the tested vapours are plotted in Figure 3. The sensor response to the on/off cycle was recorded for five cycles. The curves have a typical shape of adsorption/desorption response. The adsorption of vapour molecules causes an increase in the electrical resistance while desorption of vapour molecules results in its decrease.

The different sensitivity of the sensor towards the tested chemicals is clearly manifested in the graph. The presence of ethanol vapours produces only little change in the resistance. Acetone vapours have a small yet pronounced impact on the resistance change. By far the highest sensitivity was observed for heptane. In other words, the selectivity of the sensor was clearly confirmed by this experiment. 


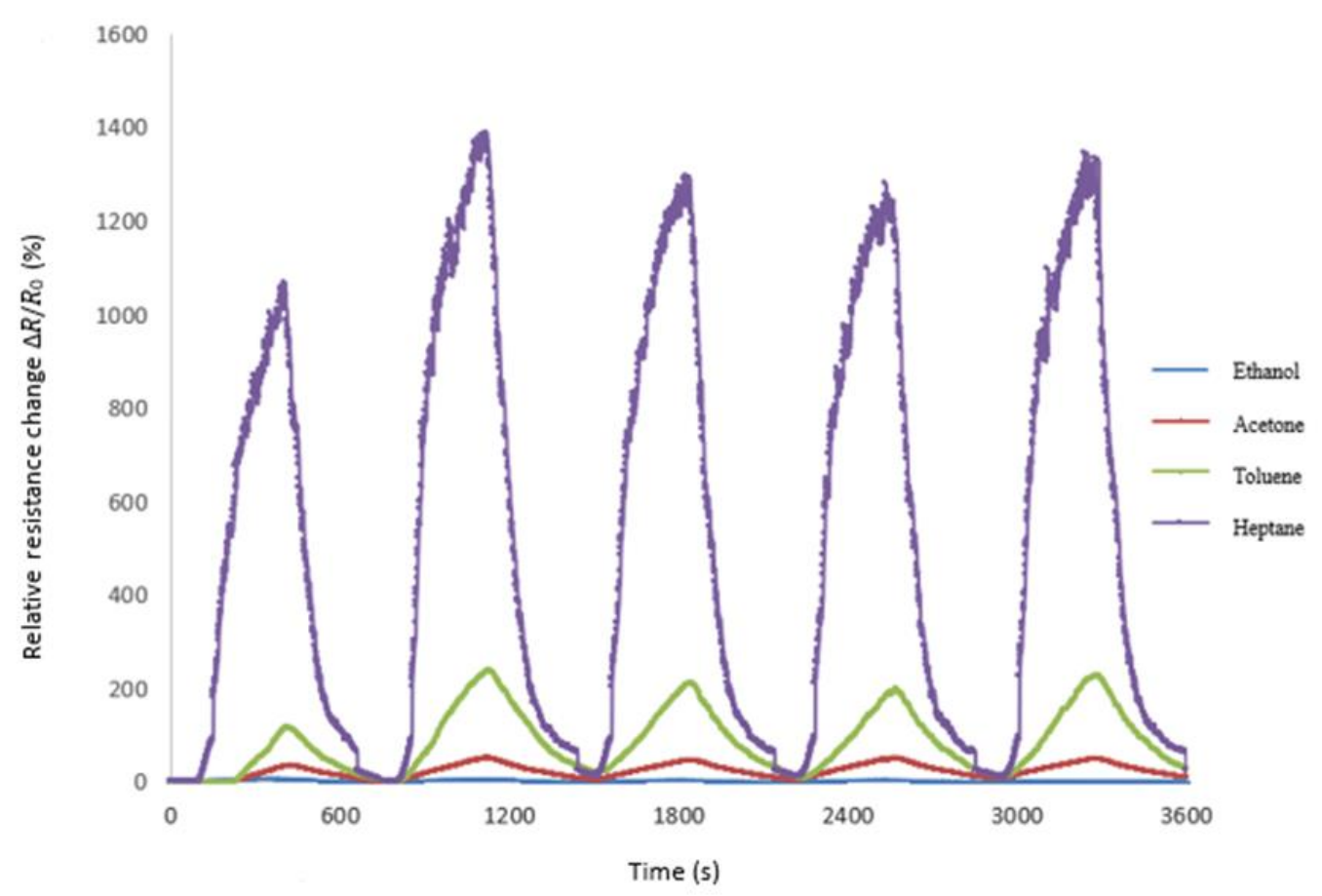

Figure 3 Time-dependent relative resistance of the MWCNT/SIS composite in the presence of heptane (purple), toluene (green), acetone (red) and ethanol (blue) during five consecutive adsorption/desorption cycles

Table 1 summarizes the maximum values $\Delta R / R_{0}$ for each solvent. The response of the sensor correlates with the hydrophobicity of the vapour molecules. Ethanol is a polar compound which does neither swell nor permeates the hydrophobic copolymer matrix. According to its molecular structure, acetone is of slightly less polar character than ethanol and is expected to permeate the copolymer matrix slowly, which results in the observed relatively small sensitivity among tested compounds. Toluene has a moderate influence on the resistance change, which is in accordance with its ability to dissolve both the styrene and isoprene blocks of the copolymer and moderate permeability through the copolymer [8]. The highest sensitivity of the sensor was observed for heptane. Heptane has the highest permeability through the copolymer among the tested chemicals, as reported earlier [8]. It is most likely due to its aliphatic hydrocarbon character that fits the molecular structure of the elastomer.

Table 1 Results of max. values $\Delta R / R_{0}$ of composite material in a given solvent

\begin{tabular}{|c|c|}
\hline Solvents & $\begin{array}{c}\Delta R / R_{0} \text { max. } \\
(\%)\end{array}$ \\
\hline Ethanol & 8 \\
\hline Acetone & 181 \\
\hline Toluene & 761 \\
\hline Heptane & 1388 \\
\hline
\end{tabular}

\section{CONCLUSION}

This work aimed to facilitate the detection of volatile organic compounds by preparation of a new nanocomposite sensor. The results proved that the composite is able to detect ambient organic vapours, which in turn characteristically alter their electrical resistance. The sensor has the highest sensitivity for the vapour of heptane, followed by nearly two times lower sensitivity to toluene. A moderate response can be observed 
for vapour of acetone, and the lowest sensitivity is experienced for the vapour of ethanol. The choice of polymer matrix imparts the selectivity to the sensor due to differences in permeability and solubility of the tested VOCs in the styrene-isoprene-styrene copolymer. The conductivity of the percolating nanotube filler network responds significantly to the swelling of the polymer matrix.

Moreover, the gas sensor developed in our research is small in size and production costs are low. It can be practically used as a part of a universal device for identification of organic solvent vapours, so called "electronic nose". Further practical use of the sensor, such as in industry, is the subject of future research.

\section{ACKNOWLEDGEMENTS}

This research was funded by the Internal Grant Agency of the Tomas Bata University in Zlin, project number IGA/CPS/2019/007, and from the national budget of the Czech Republic, within the framework of the project CPS-strengthening research capacity (reg. number: CZ.1.05/2.1.00/19.0409). This work was also supported by the Ministry of Education, Youth and Sports of the Czech Republic - DKRVO (RP/CPS/2020/006). Assoc. Prof. Ivo Kuritka, Ph.D. is greatly acknowledged for fruitful discussions and help in recording SEM images.

\section{REFERENCES}

[1] WANG, Y., YEOW, J.T.W. A review of carbon nanotubes-based gas sensors. Journal of Sensors. [Online]. 2009, vol. 2009, Article ID 493904. Available from: https://doi.org/10.1155/2009/493904.

[2] LLOBET, E. Gas sensors using carbon nanomaterials: A review. Sensors and Actuators B: Chemical. 2013, vol. 179, pp. 32-45.

[3] SEPTIANI, N.L.W., YULIARTO, B. Review-The development of gas sensor based on carbon nanotubes. Journal of the Electrochemical Society. 2016, vol. 163, no. 3, pp. B97-B106.

[4] ZAPOROTSKOVA, I.V., BOROZNINA, N.P., PARKHOMENKO, Z.N., KOZHITOV, L.V. Carbon nanotubes: Sensor properties. A review. Modern Electronic Materials. 2016, vol. 2, no. 4, pp. 95-105.

[5] PRASEK, J., DRBOHLAVOVA, J., CHOMOUCKA, J., HUBALEK, J., JASEK, O., ADAM, V., KIZEK, R. Methods for carbon nanotubes synthesis-review. Journal of Materials Chemistry. 2011, vol. 21, pp. 15872-15884.

[6] CHOUDHARY, V., GUPTA, A. Polymer/Carbon Nanotube Nanocomposites. In: YELLAMPALLI, S. (ed.). Carbon Nanotubes - Polymer Nanocomposites. Rijeka: InTech, 2011. ISBN 978-953-307-498-6. Available from: http://www.intechopen.com/books/carbon-nanotubes-polymer-nanocomposites/polymer-carbon-nanotubenanocomposites.

[7] OLEJNÍK, R., et al. Multi-wall carbon nanotube network prepared from pure MWCNT and their oxidised forms effect of compressive strain on electric resistence. In: NANOCON 2010 - 2nd International conference. Brno: TANGER Ltd., 2010, pp. 78-82.

[8] SLOBODIAN, P., RIHA, P., OLEJNIK, R. Electromechanical sensors based on carbon nanotube networks and their polymer composites. In: MUKHOPADHYAY, S.C., LAY-EKUAKILLE, A., FUCHS, A. (eds.) New Developments and Applications in Sensing Technology. New York, USA: SpringerVerlag, 2011, pp. 233-251. 